\title{
An infographic in an 'infodemic' - communication in a global pandemic with simplicity, design and speed
}

\author{
Authors: Louise Robinson ${ }^{\mathrm{A}}$ and Antonia Field-Smith ${ }^{\mathrm{A}}$
}

\section{Introduction}

The COVID-19 pandemic has presented innumerable clinical and non-clinical challenges. The global healthcare community has responded with a tsunami of guidelines as the world grapples to understand this new disease. In order to communicate in this 'infodemic', guidelines need to be simple, well designed and shared at speed.

During the surge phase of the UK COVID-19 experience, healthcare professionals were faced with communicating sensitive, difficult and emotive information to relatives on an unprecedented scale. We identified a need to support our colleagues with communicating clinical uncertainty and also breaking bad news to relatives, largely over the telephone, due to hospital visiting restrictions. Our experience as palliative care physicians enabled us to distil complex communication concepts into a simple, usable framework to support these conversations. We worked with a designer to develop a simple but visually striking guide to assist with compassionate telephone communication (Fig 1). Crucially, this also offered tips to support the healthcare professionals themselves as 'these conversations are hard'. We distributed the guide initially by hand to the wards, then via email through the trust's communications team, and then by Twitter from where it rapidly spread nationally and internationally (Table 1).

\section{Materials and methods}

A mixed methods descriptive analysis was used to look at the reach and impact of the guide extracted from the email communication and response on Twitter. Simple counts were used to summarise the quantitative data while a qualitative analysis of the comments from Twitter feeds and email communication identified themes.

\section{Results and discussion}

Qualitative thematic analysis of comments from Twitter and email revealed an overwhelmingly positive response with the following themes: a) appreciation/thanks; b) desire to share widely; c) simple and useful framework for staff; d) eye catching, colourful design; e) compassion/comfort to patient and relative; f) staff looking after

Author: ${ }^{A}$ West Middlesex University Hospital, Isleworth, UK

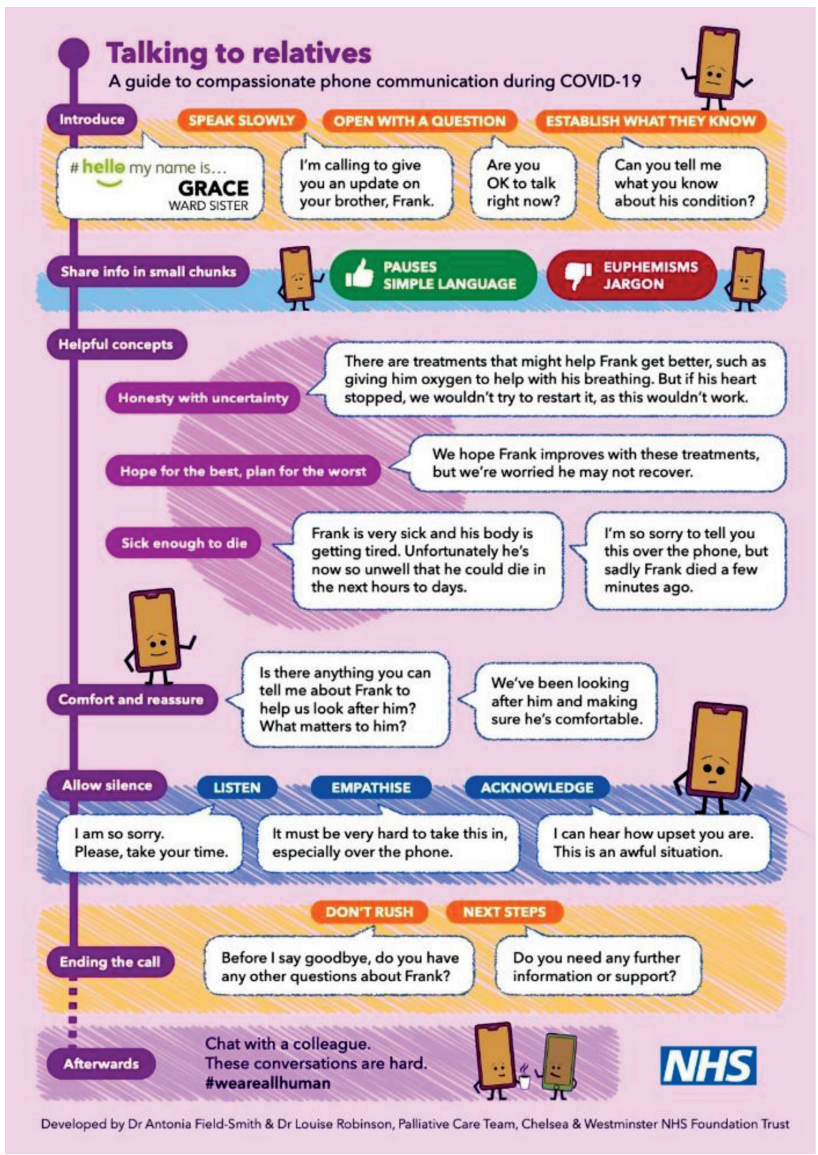

Fig 1. Talking to relatives: a guide to compassionate phone communication during COVID-19.

themselves and each other; and g) acknowledgement of difficult situation for all.

Extract of Twitter comments:

Bravo - beautiful to look at, easy to follow, full of wisdom and compassion. Thank you all.

It's a little piece of good in a time of too much bad.

None of us want it but so many of us need it.

The guide was picked up by national organisational leads requesting to adopt and publish it, including many NHS trusts 
Table 1. Response to author's original Twitter post (as of 2 October 2020)

\begin{tabular}{lllll} 
Comments & Re-tweets & Likes & Impressions & $\begin{array}{l}\text { Total } \\
\text { engagements }\end{array}$ \\
81 & 1,372 & 1,950 & 300,169 & 38,484 \\
\hline
\end{tabular}

https:/twitter.com/drantoniafs/status/1246162643158798337?s=21.

across the UK, Health in Justice, NHS England, NHS Scotland, the Faculty of Intensive Care Medicine, the British Geriatrics Society and the Patient Safety Learning Hub. International requests to adopt it were received from Europe, Australia, Canada, USA and the Philippines. The guide subsequently sparked media interest and was referenced in both the national press (The Times) and the medical literature (BMA website and magazine, $B M$ J editorial, Nursing Standard).

\section{Conclusion}

The rapid and far-reaching uptake of this communication tool exposed an unmet need. Analysis of the reach and impact suggests that its success was not only due to the communication concepts that it describes but also the simple, eye-catching design and the range of communication channels used to share it. While this guide was designed specifically in response to COVID-19, its content and application is likely to be relevant beyond this global pandemic.

\section{Conflicts of interest}

None declared. 